\title{
Modified radical retropubic prostatectomy: Personal technical variation "tension free continuum-urethral anastomosis (T.F.C.U.A)" with optical magnification in the preservation of the bladder neck, and estimation of the urinary continence
}

\author{
Alberto Roggia ${ }^{1}$, Emilio Pozzi ${ }^{1}$, Guglielmo Mantica ${ }^{1}$, Maurizio Salvadore ${ }^{2}$, \\ Dimitrios Choussos ${ }^{3}$, Carmelo Di Franco ${ }^{3}$, Carlo Maria Bianchi ${ }^{3}$ \\ ${ }^{1}$ Division of Urology - Hospital Sant'Antonio Abate - Gallarate (Va); \\ ${ }^{2}$ Division of Anatomopathology - Hospital Sant'Antonio Abate - Gallarate (Va); \\ ${ }^{3}$ Graduate School of Urology - University of Pavia.
}

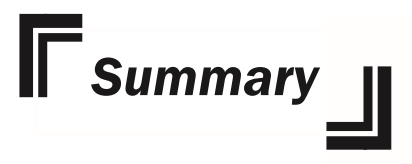

Objective: To reassess the double continence technique for open retropubic radical prostatectomy, proposed by Malizia and employed by Pagano et al., with the "tension free continuum-urethral anastomosis" (T.F.C.U.A.) personal modification and the use of image magnification optical systems and appropriate and delicate surgical tools.

Materials and methods: A total of 173 radical retropubic prostatectomies, performed by the same surgeon, were evaluated in terms of early and late continence.

Results: The presence of residual prostate cancer cells within the muscle layer was always excluded by the histopathological examination that also demonstrated that the muscle layer was well represented; satisfactory outcomes were obtained in terms of both early urinary continence $(60 \%)$ and urinary continence at 6-12 month follow-up (92.4\% for the whole series and $97.2 \%$ for the last series of patients).

Conclusions: The "tension free" anastomosis obtained by the suspension of the anterior bladder wall to the the pubis along the median line allowed to achieve satisfactory outcomes in terms of urinary continence, even if these data obviously need to be confirmed by other series and comparative trials.

KEY WORDS: Prostate cancer; Modified radical prostatectomy; Urinary continence; Double continence technique; Tension free anastomosis.

\section{INTRODUCTION}

It is well-known the importance of urethral sphincter in the preservation of the continence control and it is also known that the "success" of radical prostatectomy for prostate cancer should be defined on the evaluation of five elements including continence that are parts of the so called "pentafecta" (1).

In the classic "open" retropubic radical prostatectomy (RRP), bladder dissection from the prostate and bladder neck involves the incision of the bladder neck along its entire circumference and requires the reconstruction according to the so-called "tennis racket" technique or by multiple sutures along converging lines, in order to obtain a neo-urinary bladder neck with a caliber proportionate to the diameter of the membranous urethra. The Urology School of Padova (2) employed the "double continence technique", proposed by Malizia in 1989 (3), by carrying out a meticulous dissection of the bladderprostate furrow along its entire circumference during retrograde prostatovesciculectomy. In this way the prostate block is excised by the bladder, leaving as much as possible untouched the mucosa of the bladder neck and of the urethra, defined as "epithelial continuum". 


\section{Materials e methods}

From $1^{\text {st }}$ June 2009 to $30^{\text {th }}$ June 2012, 195 open retropubic radical prostatectomies were performed at the Department of Urology of the Gallarate Hospital: out of them 173 prostatectomies performed by a single surgeon (A.R.) were taken into account for this survey in order to obtain a more homogeneous series.

Retropubic antegrade prostatovesciculectomy was performed after opening of the endopelvic fascia, section of

Figure 1.

Isolation of the bladder-prostate epithelial continuum.

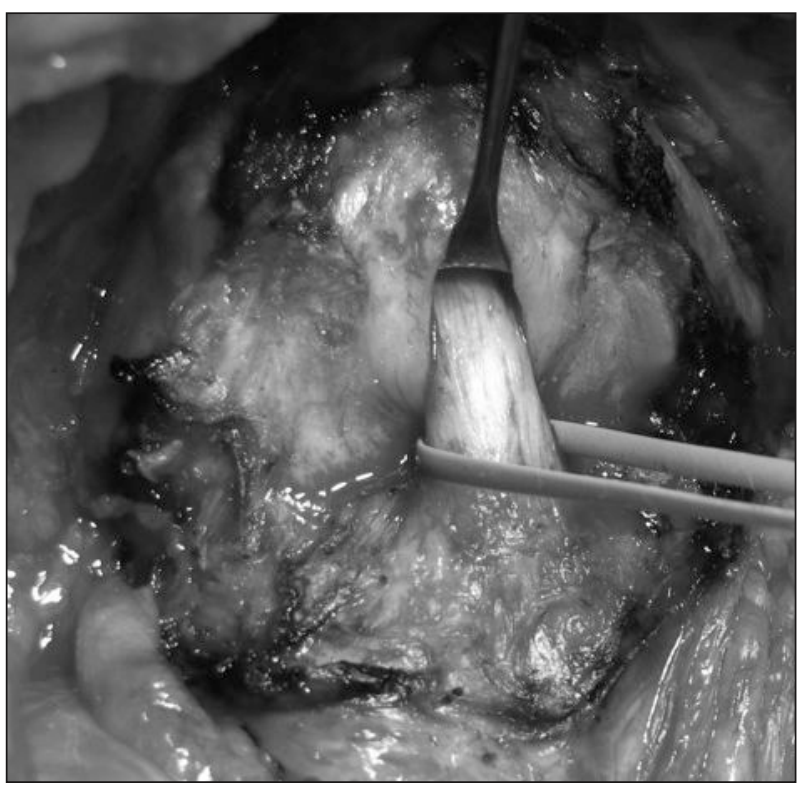

Figure 2.

Muscular structure of the bladder neck after a complete circular section along the circumference of the continuum.

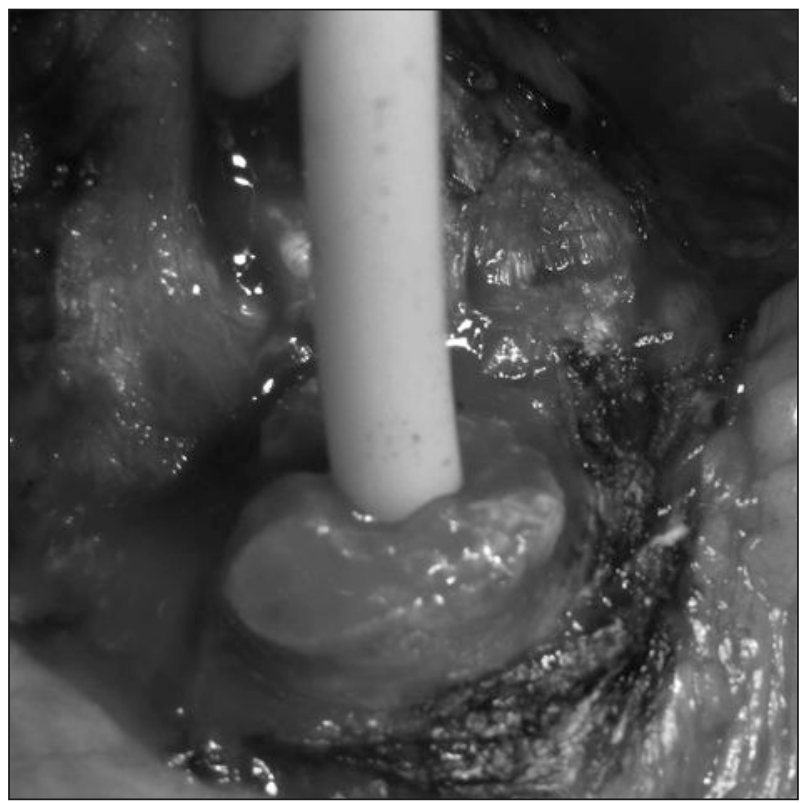

the pubo-prostatic ligaments and double ligature of the dorsal venous plexus.

In particular, the surgical technique was aimed to the careful preservation of the bladder-prostatic epithelial continuum (Figures 1, 2) by means of image magnification by a $9 \mathrm{x}$ autofocus frontal microscope or $6 \mathrm{x}$ telescopic lenses, by use of delicate surgical tools such as Metzenbaun-fino scissors and micro pliers for the dissection and at the same time by avoiding use of both mono and bipolar electrosurgical tools (since January 2012 Malis forceps, Jones I.M.A. forceps, micro forceps, Jones I.M.A. scissors, micro Spring scissors were also used in order to reach greater accuracy in the meticulous dissection at the bladder-prostate furrow level). Two stitches, that also incorporated the striated muscle of the urethra, were placed in order to fix firmly the membranous urethra to the elevator muscle of the anus; the rabdosphincter was recovered according to the technique used by Rocco (4); the anastomosis between the distal section of the continuum and the membranous urethra was obtained by single stitches after the subversion of the mucous membrane of the continuum. Occasionally an incisional biopsy was obtained in correspondence of the bladder-prostate continuum. During the procedure biopsies were marked by sutures of different colours in order to allow the pathologist to obtain sections perpendicular to the mucous surface. Histological samples were stained with hematoxylin-eosin (Figure 3) and in some cases with anti-actin and anti-desmin antibodies for the research of muscular antigens (Figure 4).

We revisited the technique described by Malizia and Pagano by adding an original modification in order to stabilize the anterior bladder wall to the pubis along the median line: a twisted absorbable suture stitch was placed between the anterior bladder wall and the pubic periosteum at a distance of $20 \mathrm{~mm}$ from the anastomosis. This original modification ("T.F.C.U.A. = tension free continuum-urethral anastomosis") aimed to relieve the tension along the anastomotic stitches between the continuum and the membranous urethra.

Urinary continence was evaluated in 171 patients (98.8\%), divided into two groups A and B. Continence was considered achieved by the use of no pads or the use of one security liner in 24 hours. In the first group (A) (135 cases), composed by patients subjected to RRP from 1 June 2009 to 31 December 2011, continence was evaluated at 12 months. In the second group (B) (36 cases), composed by patients subjected to RRP from January 2012 to June 2012, continence was evaluated after 6-12 months but also earlier after 7 days from catheter removal. Two patients were lost at follow up for urinary continence.

\section{RESULTS}

At 6-12 month follow up, out of a total of 171 patients, 158 patients were considered continent (92.4\%), while the remaining 13 patients were considered incontinent $(7.6 \%)$. Continence was higher in patients with organconfined tumors pT1-pT2, taking into account that patients with pT3-4 stages were also submitted to adjuvant therapies (radiotherapy + /- hormone therapy). 
Figure 3.

Section of an incisional biopsy of the bladder-prostate continuum: in the upper left the mucous surface (hematoxylin-eosin, x40).

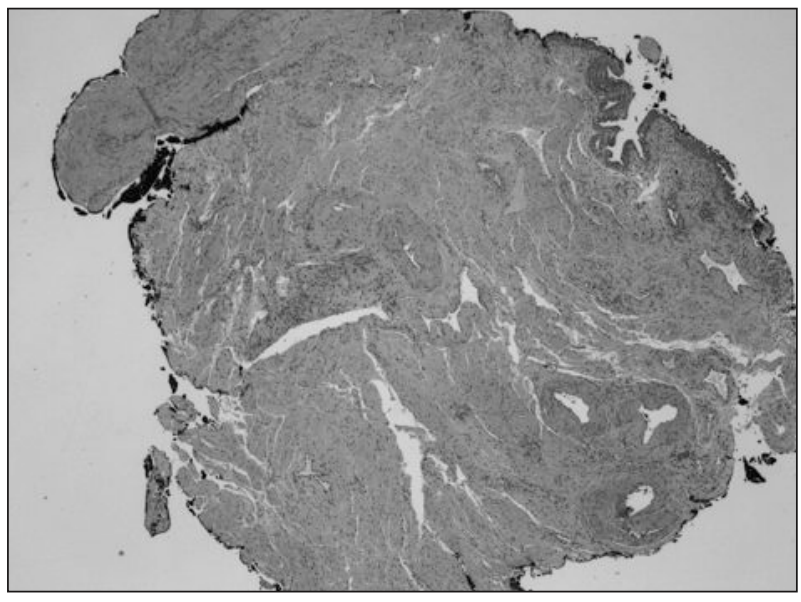

Figure 4.

Histological section of a incisional biopsy of the continuum: in evidence the muscular tunica (anti-desmin, x40).

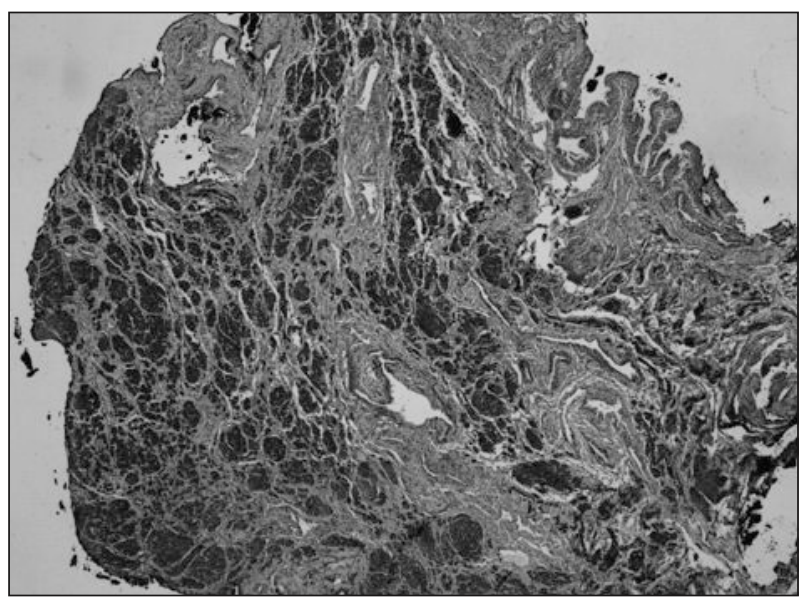

In the 135 patients of Group A, continence was present in 123 (91.1\%); in group B, which included 36 patients subjected to RRP in the first semester 2012, continence at 6 -12 month was obtained in 35 (97.2\%) while early continence after 7 days from catheter removal was observed in 21 patients $(60 \%)$ (Table 1 )

\section{Table 1.}

Personal results.

\begin{tabular}{|cccc|}
\hline Number of patients & n. 171 & n. 105 pt 1-2 & n. 66 pt 3-4 \\
\hline Continence & n. 158(92,4\%) & n. $98(93,3 \%)$ & n. $60(90,9 \%)$ \\
Group A & n. $123(91,1 \%)$ & & \\
Group B & n. 35(97,2\%) & & \\
Early continence & $60,0 \%$ & &
\end{tabular}

Histological sections, obtained by the incisional biopsies that were taken at the bladder-prostate continuum, were always negative for neoplastic infiltration; in the sections it was possible to identify the mucosa and, below it, corion and muscle layer (Figures 3, 4).

\section{Discussion}

The meticulous dissection of the bladder-prostate furrow, using appropriate systems of image magnification (5) such as $6 \mathrm{x}$ telescopic lenses or $9 \mathrm{x}$ autofocus frontal microscope, and delicate surgical tools, and avoiding mono-bipolar electrosurgical tools, allows to isolate carefully and to maintain the continuity of the bladder-urethral mucosa along the entire circumference of the bladder-prostate furrow. In this personal series, the histopathological evaluation never showed the presence of residual prostate glands or cells in this specific anatomic area, while it was clearly shown the presence of the muscle layer. It is known that the preservation of the urinary bladder neck reduces the incidence of anastomotic strictures (6) and achieves a greater incidence of early continence (65\% vs $25 \%$ ) at 4 months from the operation (7). The anastomosis between the more distal section of the continuity of the bladder-urethral mucosa and the membranous urethra is possible without reducing the lumen of the bladder neck, as the bladder neck presents a caliber proportionate to that of the urethral stump. Retropubic radical prostatectomy is associated to postoperative bladder descent (8) that could be a contributing factor to the onset of urinary stress incontinence, due to a compression of the bladder-urethral anastomosis by the bladder and the abdominal organs. In order to improve urinary continence, Tan et al. (9-10) proposed, after a series of 1383 robotic-assisted laparoscopic prostatectomies, a technical modification entitled A.R.T. (total anatomic restoration technique) which provides an antero-lateral "suspension" of the bladder with some suture stitches between the bladder itself and the pubic tendinous arch: in this way, during the urination, the contractile action of the detrusor would be distributed along several stitches, avoiding increases of pressure on the anastomosis and on the muscular urethral structures (rabdosphincter).

The approximating stitch between the anterior wall of the bladder and the pubic periosteum, that we propose (T.F.C.U.A.) in conjunction to the double continence technique used by Malizia, has the same assumption, that is to reduce the tension along the stitches of the anastomosis, but also to reduce compression on the bladder-urethral anastomosis due to the intra-abdominal pressures and the contraction of the detrusor.

In literature, rates of continence, after open retropubic surgery and robotic and laparoscopic prostatectomy, range from $38.6 \%$ to $98.5 \%$ at 3, 6, 12 and 18 months of follow-up (Table 2 ) in relation to the definition of continence used, the modality of evaluation of the functional outcome (validated questionnaires) and the population studied (multicenter versus single center survey). Hu et al. (11) in a 18-month follow up of a large series of 8.837 radical prostatectomies, including 6899 open radical prostatectomy (RRP) and 1938 minimally invasive radi- 
Table 2.

Evaluation of the continence.

\begin{tabular}{|c|c|c|c|c|c|c|c|}
\hline Tecnica & Autore & Anno & $\mathrm{n}^{\circ} \mathrm{pz}$ & 3 & 6 & 12 & $>18$ \\
\hline OPEN RRP & $\begin{array}{l}\text { Stanford (12) } \\
\text { Kundu (13) } \\
\text { Lepor (14) } \\
\text { Marien (15) } \\
\text { Touijer (16) } \\
\text { Rocco (17) } \\
\text { Krambeck (18) } \\
\text { Hu (11) }\end{array}$ & \begin{tabular}{l|}
2000 \\
2004 \\
2004 \\
2008 \\
2008 \\
2009 \\
2009 \\
2009
\end{tabular} & $\begin{array}{c}1295 \\
3477 \\
500 \\
1110 \\
222 \\
120 \\
564 \\
6899\end{array}$ & $70 \%$ & $\begin{array}{c}38.6 \% \\
87.2 \% \\
93 \%\end{array}$ & $\begin{array}{c}60.5 \% \\
93 \% \\
92.1 \% \\
\\
\\
97 \% \\
93.7 \%\end{array}$ & $\begin{array}{c}58 \% \\
98.5 \% \\
97 \% \\
95 \% \\
\\
87,80 \%\end{array}$ \\
\hline LRP & $\begin{array}{l}\text { Anestesiadis (19) } \\
\text { Lein (20) } \\
\text { Eden (21) } \\
\text { Touijer (16) } \\
\text { Krambeck (18) } \\
\text { Stolzemburg (22) } \\
\text { Mariano (23) }\end{array}$ & $\begin{array}{l}2003 \\
2006 \\
2009 \\
2008 \\
2009 \\
2009 \\
2009\end{array}$ & $\begin{array}{c}230 \\
952 \\
1000 \\
193 \\
286 \\
2400 \\
780 \\
\end{array}$ & $71.7 \%$ & $59.2 \%$ & $\begin{array}{l}89 \% \\
76 \% \\
94.9 \% \\
48 \% \\
91.8 \% \\
94.7 \% \\
87.9 \% \\
\end{array}$ & $62 \%$ \\
\hline RALP & $\begin{array}{l}\text { Ahlering (24) } \\
\text { Menon (25) } \\
\text { Patel (26) } \\
\text { Zorn (27) } \\
\text { Borin (28) } \\
\text { Krambeck (15) } \\
\text { Tewari (29) } \\
\text { Rocco (17) } \\
\text { Murphy (30 }\end{array}$ & $\begin{array}{l}2004 \\
2006 \\
2006 \\
2007 \\
2007 \\
2009 \\
2009 \\
2009 \\
2009\end{array}$ & $\begin{array}{c}202 \\
1142 \\
500 \\
300 \\
400 \\
286 \\
777 \\
120 \\
395 \\
\end{array}$ & $\begin{array}{l}77 \% \\
90 \% \\
89 \% \\
47 \% \\
89 \% \\
\\
90 \% \\
70 \% \\
\end{array}$ & $\begin{array}{l}95 \% \\
68 \% \\
97 \% \\
\\
97 \% \\
93 \%\end{array}$ & $\begin{array}{c}95 \% \\
90 \% \\
91.8 \% \\
97 \% \\
91.4 \%\end{array}$ & \\
\hline MIRP & $\mathrm{Hu}(11)$ & 2009 & 1938 & & & & $84,10 \%$ \\
\hline
\end{tabular}

cal prostatectomy (MIRP), showed a greater incontinence rate in the minimally invasive group compared to the open surgery one: $15.9 \%$ incontinence rate in the MIRP against $12.2 \%$ in the RRP, with a $\mathrm{P}$ value 0.02 .

In our experience, continence rate at 6-12-month was $92.4 \%$, with a further increase in the last series of patients (group B) in term of both early (60\%) and 6-12 month continence rate $(97.2 \%)$, and can be explained by a greater accuracy in the anatomic dissection by the use of appropriate tools and the greater experience of the surgeon.

\section{Conclusions}

It is known that optical magnification is considered one of the greater advantage of laparoscopy and that the level of accuracy of the dissection obtained by the robotic assisted procedure can make the preservation of the urinary sphincter more manageable (31).

However also the open retropubic radical prostatectomy with use of optical image magnification systems and delicate tools in order to obtain the meticulous preservation of the bladder-prostate epithelial continuum and so the preservation of the muscular sphincterial structure of the bladder neck in conjunction with a tension free anastomosis ("T.F.C.U.A.") allows to achieve satisfactory outcomes in terms of both early urinary continence (60\%) and urinary continence at 6-12 month follow-up (92.4\% for the whole series and $97.2 \%$ for the last series of patients).

However these data obviously need to be confirmed by other series and comparative trials.

\section{REFERENCES}

1. Patel VR, Sivaraman A, Coelho RF, et al. Pentafecta: a new concept for reporting outcomes of robot-assisted laparoscopic radical prostatectomy. Eur Urol. 2011; 59:702-707.

2. Pagano F, Artibani W, Zattoni F. Prostatectomia radicale per via retropubica: Tecnica chirurgica. Atlante fotografico. Edizioni MEB, 1993.

3. Malizia A. Modified radical retropubic prostatectomy: double continence technique. AUA, abstract 585, 316A, 1989.

4. Rocco F, Gregori A, Stener S, et al. Posterior reconstruction of the rhabdosfincter allows a rapid recovery of continence after transperitoneal videolaparoscopic radical prostatectomy. Eur Urol. 2007; 51:996-1003.

5. Varkarakis J, Wirtenberger W, Pinggera GM, et al. Evaluation of urinary extravasation and results after continence-preserving radical retropubic prostatectomy (RRP). BJU. 2008, 94:991-95.

6. Shelfo SW, Obek C, Soloway MS. Update on bladder neck preservation during radical retropubic prostatectomy: impact on pathologic outcome, anastomotic strictures, and continence. Urology. 1998; 51:73-78.

7. Freire MP, et al. Anatomic bladder neck preservation during robotic-assisted laparoscopic radical prostatectomy: description of technique and outcomes. Eur Urol. 2009; 56:972-980.

8. Dev HS, Sooriakumaran P, Srivastava A, Tewari AK. Optimizing radical prostatectomy for the early recovery of urinary continence. Nat Rev Urol. 2012; 9:189-95.

9. Tan GY, Jhaveri JK, Tewari AK. Anatomic restoration technique (ART): a biomechanics-based approach for early continence recovery after minimally invasive radical prostatectomy. Urology. 2009; 74:492-96. 
10. Tan GY, Srivastana A, Grover S, et al. Optimizing vescico-urethral anastomosis healing after robot-assisted laparoscopic radical prostatectomy: lessons learned from three techniques in 1900 patients. J Endourol. 2010; 12:1975-1983.

11. Hu JC, Gu X, Lipsitz SR, et al. Comparative effectiveness of minimally invasive vs open radical prostatectomy. JAMA. 2009; 302:1557-1564.

12. Stanford JL, Feng Z, Hamilton AS, et al. Urinary and sexual function after radical prostatectomy for clinically localized prostate cancer: the prostate cancer outcomes study. JAMA. 2000; 283:354-60.

13. Kundu SD, Roehl KA, Eggener SE, et al. Potency, continence and complications in 3477 consecutive radical retropubic prostatectomies. J Urol. 2004; 172:2227-31.

14. Lepor $H$, Kaci L. The impact of open radical retropubic prostatectomy on continence and lower urinary tract symptoms: a prospective assessment using validated self-administered outcome instruments. J Urol. 2004; 171:1216-9.

15. Marien TP, Lepor H. Does a nerve-sparing technique or potency affect continence after open radical retropubic prostatectomy? BJU Int. 2008; 102:1581-84.

16. Touijer K, Eastham JA, Secin FP, et al. Comprehensive prospective comparative analysis of outcomes between open and laparoscopic radical prostatectomy conduced in 2003 to 2005. J Urol. 2008; 179:1811-7.

17. Rocco B, Matei DV, Melegari S, et al. Robotic vs open prostatectomy: a systematic review and cumulative analysis of comparative studies,. Eur Urol. 2009; 104: 991-5.

18. Krambeck AE, Di Marco DS, Rangel LJ, et al. Radical prostatectomy for prostatic adenocarcinoma: a matched comparison of open retropubic and robot-assisted techniques. BJU Int. 2009; 103:448-53.

19. Anestesiadis AG, Salomon L, Katz R, et al. Radical retropubic versus laparoscopic prostatectomy: a prospective comparison of functional outcome. Urology. 2003; 62:292-7.

20. Lein M, Stibane I, Mansour R, et al. Complications, urinary continence, and oncologic out come of 1000 laparoscopic transperitoneal radical prostatectomies-experience at the Charite Hospital Berlin, Campus Mitte. Eur Urol. 2006; 50:1278-82.

21. Eden CG, Neill MG, Louie-Johnsun MW. The first 1000 cases of laparoscopic radical prostatectomy in the UK: evidence of multiple "learning curves". BJU Int. 2009; 103:1224-30.

22. Stolzemberg JU, Kallidonis P, Minh D, et al. Endoscopic extraperitoneal radical prostatectomy: evolution of the technique and experience with 2400 cases. J Endourol. 2009; 23:1467-72.

23. Mariano MB, Tefilli MV, Fonseca GN,Goldraich IH. Laparoscopic radical prostatectomy: 10 years experience. Int Braz J Urol. 2009; 35:565-72.

24. Ahlering TE, Skarecky D, Lee D, Clayman RV. Successful transfer of open surgical skills to a laparoscopic environment using a robotic interface: initial experience with laparoscopic radical prostatectomy. J Urol. 2003; 170:1738-41.

25. Menon M, Shrivastava A, Kaul S, et al. Vattikuti Institute prostatectomy: contemporary technique and analysis of results. Eur Urol. 2007; 51:648-58.

26. Patel VR, Thaly R, Shah K. Robotic radical prostatectomy: outcomes of 500 cases. BJU Int. 2007; 70:173-7.

27. Zorn KC, Gofrit ON, Orvieto MA, et al. Robotic-assisted laparoscopic prostatectomy: functional and pathologic outcomes with interfascial nerve preservation. Eur Urol. 2007; 51:755-62.
28. Borin JF, Skarecky DW, Narula N, Alhering TE. Impact of urethral stump length on continence and positive surgical margins in robot-assisted laparoscopic prostatectomy. Urology. 2007; 70:173-7.

29. Tewari A, Jhaveri J, Rao S, et al. Total reconstruction of the vesico-urethral junction. BJU Int. 2008; 101:871-877.

30. Murphy DG, Kerger M, Crowe H, et al. Operative details and oncological and functional outcome of robotic-assisted laparoscopic radical prostatectomy: 400 cases with a minimum of 12 months follow-up. Eur Urol. 2009; 55:1358-66.

31. Ficarra V, Novara G, Mottrie A, Artibani W. Robotic and laparoscopic prostatectomy: A critical review of existing data. AUA Update Series. 2010, 29 (lesson 30). 